\title{
Non-Coding RNAs: IncRNAs, miRNAs, and piRNAs in Sexual Development
}

\author{
Miguel Burgos $^{\text {a }}$ Alicia Hurtado $^{b}$ Rafael Jiménez ${ }^{a}$ Francisco J. Barrionuevo ${ }^{a}$ \\ aDepartamento de Genética e Instituto de Biotecnología, Lab. 127, Centro de Investigación Biomédica, Universidad \\ de Granada, Granada, Spain; ${ }^{b}$ Epigenetics and Sex Development Group, Berlin Institute for Medical Systems Biology, \\ Max-Delbrück Center for Molecular Medicine, Berlin, Germany
}

\section{Keywords}

Long non-coding RNA · microRNA · Non-coding RNA · PIWIinteracting RNA $\cdot$ Sex determination $\cdot$ Sex differentiation

\begin{abstract}
Non-coding RNAs (ncRNAs) are a group of RNAs that do not encode functional proteins, including long non-coding RNAs (IncRNAs), microRNAs (miRNAs), PIWI-interacting RNAs (piRNAs), and short interfering RNAs (siRNAs). In the last 2 decades an effort has been made to uncover the role of ncRNAs during development and disease, and nowadays it is clear that these molecules have a regulatory function in many of the developmental and physiological processes where they have been studied. In this review, we provide an overview of the role of ncRNAs during gonad determination and development, focusing mainly on mammals, although we also provide information from other species, in particular when there is not much information on the function of particular types of ncRNAs during mammalian sexual development.

(c) 2021 S. Karger AG, Basel
\end{abstract}

(c) 2021 S. Karger AG, Base

www.karger.com/sxd

\section{Introduction}

Mammalian genomes contain long extensions of noncoding DNA that were once considered "junk DNA". However, evidence has accumulated showing that this "genomic dark matter" is anything but junk. A large portion of this DNA is transcribed into long and short RNA molecules that do not code for proteins but regulate a variety of biological processes such as transcription and translation, chromatin folding, gene silencing, and epigenetics, among others. Kapranov et al. [2007] and Necsulea et al. [2014] found that a high proportion of different non-coding, or at least non-annotated, RNAs (ncRNAs) are present in the cells, reaching up to 4-times the amount of unique mRNAs. Despite this difference, ncRNAs represent only about $10 \%$ of the total RNA in a given cell [Cabili et al., 2011], perhaps because ncRNAs have a more cell-specific expression than mRNAs [Ravasi et al., 2006]. ncRNA have been classified according to their length. Those longer than 200 nucleotides are named long non-coding RNAs (lncRNAs) and their loci may be located anywhere in the genome, either inside other genes, in the opposite strand, inside introns, or in intergenic regions. In the later case, they are named long in-

\footnotetext{
Karger"
}

Correspondence to:

Rafael Jiménez, rjimenez@ugr.es 
Fig. 1. Types of RNA including their relative abundance in the cell (percentages are relative to the complete genome). ncRNA, non-coding RNA; miRNA, microRNA; snoRNA, small nucleolar RNA; snRNA, small nuclear RNA; tRNA, transfer RNA; rRNA, ribosomal RNA; piRNA, PIWI-interacting RNA; circRNA, circular RNA; Y RNA, components of the Ro60 ribonucleoprotein particle. Numeric data taken from Seal et al. [2020] and Uchida and Dimmeler [2015].

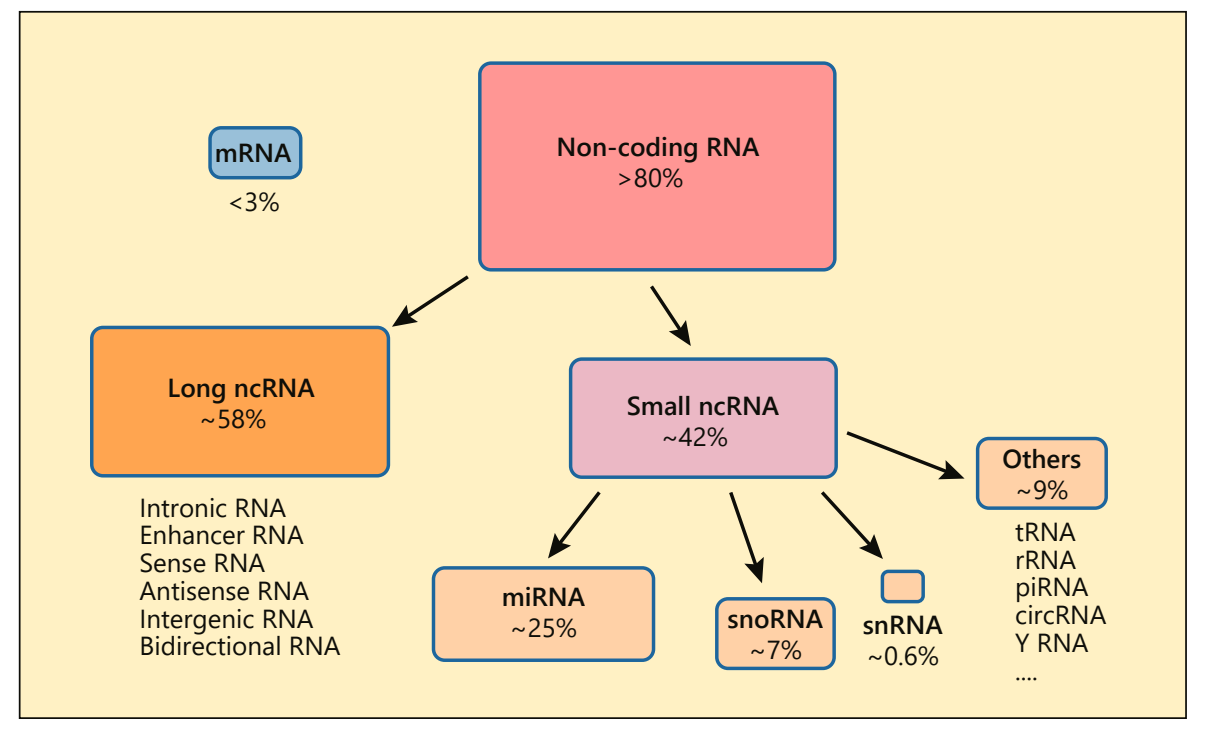

tergenic non-coding RNAs (lincRNA). When shorter than 200 nucleotides, they are referred to as short noncoding RNAs, a heterogenous group that includes microRNAs (miRNAs), PIWI-interacting RNAs (piRNAs), or short interferring RNAs (siRNAs). Figure 1 summarizes the different types of RNA and their relative abundance.

Small ncRNAs that can bear syalinated glycans have very recently been discovered [Flynn et al., 2021]. These glycoRNAs are present in the cell membrane of many different cell types and tissues. The ubiquitous localization in a great variety of cells and tissues opens the possibility that they may play important roles in the testis, an organ in which intercellular communication is crucial.

In this review, we outline the role of ncRNAs in gonadal development, focusing on gonadal sex determination and differentiation. The genetic control of these developmental processes have been extensively reviewed and the reader is therefore referred to recent reviews for an update [Lin and Capel, 2015; Windley and Wilhelm, 2015; Carré and Greenfield, 2016; She and Yang, 2017; Miyawaki and Tachibana, 2019].

\section{microRNAs}

miRNAs are small ncRNAs that play essential roles in a wide range of biological processes. The biogenesis and mechanism of action of miRNAs have been widely reviewed [Bushati and Cohen, 2007; Kim et al., 2009; Ha and Kim, 2014; O'Brien, 2018]. Briefly, most of them are transcribed by RNA polymerase II as primary precursors, the pri-miRNAs, which are initially processed in the nucleus by the Microprocessor, a protein complex composed of the ribonuclease enzyme DROSHA and the dimeric RNA-binding protein DGCR8, to form the precursor miRNAs (pre-miRNAs). Subsequently, pre-miRNAs are exported to the cytoplasm, a process mediated by exportin 5, where they are further processed by the RNase III-endonuclease Dicer, releasing 22-nucleotide (nt) miRNA duplexes. A miRNA duplex is loaded onto an Ago protein forming the effector complex, the RNA-induced silencing complex, RISC. During this process, one strand of the duplex remains in Ago as the guide, whereas the other, the so called passenger strand, is degraded. Within the RISC complex, the seed sequence of the guided strand (nt 2-8) binds to the $3^{\prime}$ untranslated region (UTR) of its target mRNA by sequence complementarity resulting in translational repression or mRNA degradation. The role of miRNAs in mammalian gonadal sex determination and differentiation has been the subject of extensive research in the last decade. Many expression profiling studies indicate that miRNAs play essential roles in gonadal development. These include specific testis and ovary miRNA signatures and differential expression analyses at key stages of gonad development performed in a variety of mammalian species, including mouse [Ro et al., 2007; Yan et al., 2007; Mishima et al., 2008; Song et al., 2009; Buchold et al., 2010], sheep [Torley et al., 2011; Bai et al., 2019], pig [Lian et al., 2012; Ran et al., 2015; Ding et al., 2020], human [Yang et al., 2013], and dog [Kasimanickam and Kasimanickam, 2015]. 
Here, we will focus exclusively on mammalian gonadal sex determination and differentiation, and no discussion on the roles of miRNAs in either the function of the adult mammalian testis or the mechanisms of sex determination in non-mammalian species will be included.

\section{Lessons from Dicer, Drosha, and Dgcr8 Ablation}

Additional evidence of the role of miRNAs in gonad development came from the analysis of mice with a targeted deletion of the RNase III-endonuclease Dicer. Homozygous mice with a null mutation for the Dicerl gene die early in development, at embryonic day 7 (E7) [Bernstein et al., 2003], and thus, the analysis of the sexual differentiation process, which starts at E10, is prevented. Alternatively, Dicer 1 has been conditionally deleted in somatic and germ cells at different stages. The key event of mammalian sex determination occurs in the supporting cell lineage of the undifferentiated gonadal primordium, which can differentiate as either Sertoli cells in the testis or granulosa cells in the ovary. In somatic cells, Dicer 1 was ablated either during or shortly after the stage of gonadal sex determination by using a Nr5a1-Cre allele [Huang et al., 2009] or an Amh-Cre allele [Papaionuou et al., 2009; Kim et al., 2010], respectively. In all cases, Dicer 1 null Sertoli cells showed normal embryonic development, and at $\mathrm{P} 0$, mutant testis tubules were undistinguishable from controls. Subsequently, Dicer1-mutant testes show a progressively aberrant development, and by P5, many testis cords were almost completely degenerated with the loss of both Sertoli and germ cells. These results showed that Dicer was necessary for postnatal Sertoli cell development; however, it could not be ruled out a role for the protein during embryonic testis development, as many miRNAs showed a substantial half-life in the fetal testis, and they were still present in Sertoli cells even at P6 [Pappaionuou et al., 2009]. In Nr5a1-Cre;Dicer mutant mice, the enzyme was ablated in both Leydig (the steroidogenic cells of the testis) and supporting cell lineages, as the Nr5al gene product, the steroidogenic factor NR5A1 (also called SF1), is expressed in both cell types. In these mutant mice, most of Leydig cells had disappeared by P2 and no Leydig cells were found by P5, indicating an essential role for miRNAs also in Leydig cell development [Huang and Yao, 2010]. In male germ cells, 2 groups initially deleted Dicer 1 using a primordial germ cell-specific Cre recombinase allele, TNAP-Cre, both resulting in subfertility [Hayashi, 2008; Maatouk et al., 2008]. However, whereas one of them reported spermatogenic arrest caused by defective proliferation and/or differentiation of spermatogonia as the underlying cause of subfertility

Non-Coding RNAs in Sexual Development
[Hayashi, 2008], the other one found that the transition from round to elongating spermatids was defective and that sperm exhibited abnormal motility in germ cell $\mathrm{mu}-$ tants [Maatouk et al., 2008]. A further study used a Ngn3Cre allele to delete Dicer1 during early postnatal development in spermatogonia and found (1) that the number of haploid cells had decreased in mutant testes, and (2) that chromatin organization and nuclear shaping of elongating spermatids was abnormal [Korhonen et al., 2011].

Embryonic ovarian development in the absence of Dicer was also assessed in Nr5a1-Cre; Dicer mice, as Nr5a 1 is also expressed in early somatic cells of the ovary. Conditional mutant mice presented a normal ovarian development until P5 stage at which they died, indicating that somatic Dicer is dispensable for proper ovarian development. However, this is not clear, as the possibility exists, again, that miRNAs were very stable in embryonic Dicerdeleted somatic ovarian cells. In contrast, in the postnatal ovary, deletion of Dicer in granulosa cells using an Am$\mathrm{hr}$-Cre allele resulted in decreased ovulation rate, trapped oocytes in luteinized follicles, and increased numbers of atretic follicles, indicating that miRNA function is necessary for proper granulosa function after birth [Nagaraja et al., 2008; Lei et al., 2010]. On the other hand, germ cellspecific deletion of Dicer shortly after the initiation of oocyte growth using a Zp3-Cre transgene resulted in meiotic arrest with multiple disorganized spindles and severe chromosome congression defects that led to infertility [Murchison et al., 2007].

Besides Dicer, Drosha and Dgcr8 also have been targets for disrupting miRNA expression during gonadal development. As mentioned above, DROSHA and DGCR8 form the Microprocessor, which is nuclear and cleaves pri-miRNAs to produce pre-miRNAs, while Dicer is cytoplasmic and cleaves pre-miRNAs to produce mature miRNAs. Dicer also cleaves double-stranded RNAs (dsRNAs) into other types of small RNAs, such as small interfering RNAs (siRNAs), and endo-siRNAs [Carthew and Sontheimer, 2009]. Nevertheless, there are certain miRNA subclasses whose biogenesis is either Drosha- or Dicer-independent [Ruby et al., 2007; Cheloufi et al., 2010; Chong et al., 2010; Cifuentes et al., 2010], and both Drosha and Dicer also have miRNA-independent functions [Tam et al., 2008; Watanabe et al., 2008]. Wu et al. [2012] compared the effects of deleting Drosha and Dicer in postnatal germ cells of the mouse testis and, unexpectedly, Drosha mutant testes were more severely disrupted than Dicer 1 mutant ones, indicating that endo-siRNAs may have a protective role in spermatocytes and round spermatids. Nevertheless, the time course and severity of 
spermatogenic alterations were very similar in both mutants, as expected for 2 enzymes which are involved in the same pathway. In a further study, Zimmermann et al. [2014] compared the effects of the deletion of Dicer and Dgcr8 in postnatal male germ cells. Dicer and Dgcr8 mutant mice also showed similar spermatogenic defects and were infertile, although in this case the testicular phenotype of $D g c r 8$ mutants were less severe than that of Dicer ones. These findings contradict the results of $\mathrm{Wu}$ et al. [2012], and the authors argued that the use of different Cre-transgenic lines, the different mouse genetic background, and/or small RNA-independent functions of DROSHA could account for these differences. In any case, it is clear that endo-siRNAs have a role during male germ cell development and function. In contrast, Drosha has also been conditionally inactivated in oocytes of developing ovaries but no apparent ovarian phenotype was detected, indicating that it is dispensable for postnatal follicular development and female fertility in adulthood [Yuan et al., 2014]. This greatly contrasts with the situation in equivalent Dicer mutants which, as mentioned above, exhibit disrupted meiosis leading to female infertility. This big discrepancy in the findings is intriguing as both Drosha and Dicer are involved in miRNA production. The explanation could rely on their non-overlapping functions, including endo-siRNA production and perhaps other unknown ones that might account for these differences [Yuan et al., 2014].

\section{Role of Specific miRNAs in Mammalian Gonadal Sex Determination}

Two groups initially searched for differentially expressed miRNAs at the period of gonadal sex determination in mice between E11.5 and E13.5. Rakoczy et al. [2013] sequenced small RNAs extracted from XY and XX mouse fetal gonads between E11.5 and E13.5 and found 46 miRNAs differentially expressed between testes and ovaries. Among them, 23 were univocally identified within the mouse genome, of which 17 were testis-enriched and 6 ovary-enriched (Table 1). In the second study, Real et al. [2013] performed a microRNA profiling of E11.5 and E13.5 mouse gonads using microarrays and found 71 miRNAs with differential expression either between sexes or between developmental stages. Among them, 20 miRNAs were differentially expressed in a sex-specific manner at 13.5, of which 6 were upregulated in testes and 14 upregulated in ovaries (Table 1 ). Surprisingly, $m i R$ 202 was the only sexually dimorphic miRNA identified in the 2 studies (Table 1). Rakoczy et al. [2013] subsequently focused on the study of $m i R-140-3 p$ during testis deter- mination, the testis enriched miRNA with highest expression identified in their study. They found that its opposing strand, $m i R-140-5 p$, was also testis enriched, albeit at a much lower extent. Both miRNAs were expressed in testis cords, but targeted deletion of $m i R-140$ in male mice resulted in normal testis cord development. A closer examination of the mutant testes revealed an increase in Leydig cell numbers at E13.5. This phenotype was similar to that of testes with disrupted Notch signaling [Tang et al., 2008], and several genes belonging to this pathway are predicted to be targeted by either $m i R-140-5 p$ or $m i R$ $140-3 p$, indicating that both miRNAs may regulate the expression of factors produced by Sertoli cells that influence the Leydig cells differentiation through the Notch signaling. The same group also studied the role of $m i R$ 202-5p and $m i R-202-3 p$ during early gonad differentiation [Wainwright et al., 2013]. pri-miR-202 had been found to be strongly expressed in Sertoli cells and weakly expressed in the ovary, but ectopic expression of $m i R-202$ in ovaries did not induce alterations of the ovary determination pathway. Expression analysis and promoter studies revealed that pri-miR-202 may be a direct transcriptional target of SOX9/SF1 during testis differentiation, and $m i R-202$ has been shown to repress the WNT signaling pathway in human Sertoli cells [Yang and Sun, 2019], indicating that this miRNA may have a role in maintaining the sexual male fate in Sertoli cells.

On the other hand, Real et al. [2013] studied the role of $m i R-124$ during gonadal sex determination, a miRNA that their microarray profiling showed to be upregulated in the ovary and downregulated in the testis [Table 1]. Sexually dimorphic expression was found at E13,5 but not at E11,5, which is too late to play a role in testis determination but not to be involved in early ovary differentiation. This miRNA had been previously shown to regulate Sox9 expression in the brain [Cheng et al., 2009], and antagomir inhibition of miR-124 in E13.5 XX gonadal cells resulted in Sox 9 upregulation, indicating that this miRNA is sufficient to induce the repression of Sox 9 in ovarian cells. The mouse genome contains 3 miR-124 genes that give rise to the same mature sequence. All 3 miR-124 genes were expressed in E13.5 mouse ovaries, mainly pre-miR-124a-2. However, no XX sex reversal was reported in mutant null mice for $m i R-124 a-1$ in a study on the function of $m i R-124 a$ in areas of the central nervous system [Sanuki et al., 2011]. It would be interesting to study triple null mutant mice to uncover the role of this miRNA in ovary development in vivo.

From the testis-enriched miRNAs identified by Rakoczy et al. [2013], miR-130a has also been shown to play 
Table 1. Differentially expressed miRNAs in testes and ovaries at several developmental stages around the time of mouse sex determination according to 3 profiling studies

\begin{tabular}{|c|c|c|c|}
\hline \multirow[t]{2}{*}{ Stage } & \multicolumn{2}{|l|}{ Whole gonad } & \multirow{2}{*}{$\frac{\text { Somatic cells }}{\text { Fernández-Pérez et al. [2018] }}$} \\
\hline & Rakoczy et al. [2013] & Real et al. [2013] & \\
\hline \multicolumn{4}{|c|}{ Upregulated in testis } \\
\hline E11.5 & $\begin{array}{l}\operatorname{miR}-130 a \\
\operatorname{miR}-434-5 p \\
m i R-872\end{array}$ & & \\
\hline E12.5 and E13.5 & $\begin{array}{l}\operatorname{miR}-202-3 p \\
\operatorname{miR}-202-5 p\end{array}$ & & \\
\hline E13.5 & $\begin{array}{l}\text { miR-140-5p } \\
\text { miR-140-3p } \\
\text { miR-470 } \\
\text { miR-871 } \\
\text { miR-743a } \\
\text { miR-540-3p } \\
\text { miR-465a-5p } \\
\text { miR-184 } \\
\text { miR-741 } \\
\text { miR-743b-3p } \\
\text { miR-878-5p } \\
\text { miR-485 }\end{array}$ & $\begin{array}{l}\text { miR-455 } \\
\text { miR-144 } \\
\text { miR-184 } \\
\text { miR-202-3p } \\
\text { miR-455 } \\
\text { miR-193 }\end{array}$ & $\begin{array}{l}\text { miR-19a-3 } \\
\text { miR-22-3p } \\
\text { miR-30a-5p } \\
\text { miR-30d-5p } \\
\text { miR-30e-5p } \\
\text { miR-125a-3p } \\
\text { miR-139-5p } \\
\text { miR-140-5p } \\
\text { miR-149-5p } \\
\text { miR-185-5p } \\
\text { miR-202-3p } \\
\text { miR-204-5p } \\
\text { miR-214-3p } \\
\text { miR-500-3p } \\
\text { miR-532-3p } \\
\text { miR-532-5p } \\
\text { miR-665-3p } \\
\text { miR-667-3p }\end{array}$ \\
\hline \multicolumn{4}{|c|}{ Upregulated in ovary } \\
\hline E11.5 & $\begin{array}{l}\operatorname{miR}-485 \\
\operatorname{miR}-423-5 p\end{array}$ & & $\begin{array}{l}\text { miR-103-3p } \\
\text { let-7g-5p } \\
\text { miR-107-3p } \\
\text { miR-26a-5p }\end{array}$ \\
\hline E12.5 & $\begin{array}{l}\operatorname{miR}-878-5 p \\
\operatorname{miR}-28 \\
\operatorname{miR}-378\end{array}$ & & \\
\hline E13.5 & $\operatorname{miR}-206$ & $\begin{array}{l}\text { miR-135a } \\
\text { miR-124 } \\
\text { miR-38 } \\
\text { miR-878-3p } \\
\text { miR-96 } \\
\text { miR-471 } \\
\text { miR-742 } \\
\text { miR-743a } \\
\text { miR-741 } \\
\text { miR-182 } \\
\text { miR-672 } \\
\text { miR-183 } \\
\text { miR-880 } \\
\text { miR-881 }\end{array}$ & \\
\hline
\end{tabular}

Non-Coding RNAs in Sexual Development 
Table 2. Human miRNAs with potential conserved 3' UTR targets in genes with key roles in mammalian gonad development

\begin{tabular}{|c|c|c|c|}
\hline$S R Y$ & 134 & - & - \\
\hline soxg & 2,033 & $\begin{array}{l}\text { miR-101-3p,miR-138-5p,miR-1-3p/miR-206/miR- } \\
\text { 613,miR-145-5p/miR-5195-3p, miR-302-3p/miR-520- } \\
\text { 3p,miR-30-5p }\end{array}$ & $\begin{array}{l}\text { miR-101-3p; lung cancer [Kong et al., 2019b] } \\
\text { miR-138-5p; hepatocellular carcinoma, renal cell carcinoma } \\
\text { [Liu et al., 2016; Hu et al., 2017] } \\
\text { miR-1-3p; hepatocellular carcinoma, developmental } \\
\text { dysplasia of the hip (DHH) [Zhang et al., 2019] } \\
\text { miR-206; lung cancer, Legg-Calvé-Perthes disease, hepato- } \\
\text { cellular carcinoma [Zhang et al., 2015b, 206; Luo et al., 2018; } \\
\text { Lin et al., 2021] } \\
\text { miR-613; glioma, hepatocellular carcinoma, gastric cancer [Li } \\
\text { et al., 2019; Sang et al., 2018; Xue et al., 2019] } \\
\text { miR-145-5p; chondrogenic differentiation, cartilage } \\
\text { develop-ment [Yang et al., 2011; Martinez-Sanchez et al., } \\
\text { 2012; Rani et al., 2013; Cui et al., 2021;Wang and Yang, 2020] } \\
\text { miR-30-5p; lung cancer, colon cancer [Zhou et al., 2019; Sun } \\
\text { et al., 2020] }\end{array}$ \\
\hline
\end{tabular}

FGF9 $3,066 \quad$ miR-140-5p, miR-182-5p
miR-425-5p, miR-96-5p/miR-1271-5p, miR-302-3p/miR-
372-3p/miR-373-3p/miR-520-3p, miR-187-3p, miR-4995p, miR-183-5p, miR-155-5p, miR-140-3p, miR-219-5p/ miR-4782-3p/miR-6766-3p, miR-9-5p, miR-137, miR-15-5p/ miR-16-5r/miR-195-5p/miR-424-5p/miR-497-5p/miR-68385p, miR-143-3p/miR-4770/miR-6088

miR-140-5p; hepatocellular carcinoma, laryngeal squamous cell carcinoma, lung cancer, bladder cancer, odontoblastic differentiation [Yang et al., 2013; Wang et al., 2019; Li et al., 2020; Wu et al., 2020b; Zhong et al., 2020]

miR-182-5p; Schwann cell, hallux valgus deformity [Yu et al., 2012; Zhang et al., 2021]

miR-372-3p; lung squamous cell carcinoma (LSCC) [Wang et al., 2017]

miR-187-3p; cervical cancer, non-small-cell lung cancer (NSCLC), breast cancer [Liang et al., 2017; Liang et al., 2020; Wu et al., 2020c]

\begin{tabular}{|c|c|c|c|}
\hline FOXL2 & 1,368 & $\begin{array}{l}\text { miR-23-3p/miR-130-5p,iR-133a-3p.1, miR-133a-3p.1/ } \\
\text { miR-133b, miR-302-3p/miR-372-3p/miR-373-3p/miR-520- } \\
\text { 3p, miR-17-5p/miR-20-5p/miR-51/miR-93-5p/miR-106-5p/ } \\
\text { miR-519-3p/miR-526-3p }\end{array}$ & $\begin{array}{l}\text { miR-133a; differentiation of C2C12 cells [Luo et al., 2015] } \\
\text { miR-133b; estrogen production in granulosa cells [Dai et al., } \\
\text { 2013] }\end{array}$ \\
\hline DMRT1 & 951 & - & - \\
\hline PTGDS & 164 & - & - \\
\hline
\end{tabular}

miRNAs whose target has been validated in experimental studies are shown in bold font.

a role in testis development. In a study using an EdUbased high-content screening assay, miR-130a was identified as an inducer of immature porcine Sertoli cell proliferation [Luo et al., 2020]. In vitro assays showed that $m i R-130 a$ induced cell cycle progression and cell proliferation and protected immature porcine Sertoli cells from apoptosis. Furthermore, tandem mass tags (TMT) protein analysis identified several molecular pathways regulated by $m i R-130 a$, including TGF- $\beta$ and PI3K/AKT sig- naling. As TGF- $\beta$ signaling plays an essential role in ovary development [Kashimada et al., 2011], it is plausible to think that this miRNA plays a role during testis determination/differentiation by inhibiting the translation of genes belonging to this pathway.

More recently, a third small transcriptome profiling study during the gonadal sex determination period of mice has been carried out. In this case, somatic and primordial germ cells were analyzed separately [Fernández- 
Pérez et al., 2018]. The authors found that 257 and 65 miRNAs were up- and downregulated, respectively, in female somatic cells compared to male ones, whereas for primordial germ cells, 198 and 47 miRNAs were downand upregulated, respectively, in females compared to males. Some examples are shown in Table 1. In particular, at E11.5, coinciding with the moment of gonadal sex determination in mice, 248 miRNAs were upregulated in female somatic cells compared to male ones, indicating that miRNAs confer robustness to the female pathway through the inhibition of target male pathway genes at the critical window of ovary determination. Interestingly, $m i R-103-3 p$ was among these genes, a miRNA which targets $F g f 9$, a critical factor for testis differentiation [Colvin et al., 2001].

Despite all this knowledge, nowadays no single miRNA or miRNA family (group or miRNAs with a common seed sequence) have been shown to play an essential role in gonadal sex determination. For this to occur, candidate miRNAs would have to regulate gene/s involved in the initial steps of sex determination. In this context, $S R Y$ does not seem to be a good putative target for miRNAs, as this gene does not appear to have a $3^{\prime}$ UTR in many species and, accordingly, no conserved predicted binding site for any miRNA have been found in this region (Table 2). Other male pathway genes, such as DMRT1 and PTGDS, are in the same situation, and it is unlikely that their expression is regulated by miRNAs. In contrast, other genes, such as SOX9 and FGF9, have long 3' UTR regions containing many conserved predicted binding sites for different miRNAs, which in many cases are validated in other tissues (Table 2), indicating that they are good candidates for miRNA regulation. On the other hand, genes necessary for ovary determination and differentiation including FOXL2 and WNT4 also contain many miRNAs conserved predicted binding sites, whereas RSPO1 only has 2 of them. Altogether, these observations indicate that the role of miRNAs in mammalian gonadal sex determination may be a complex process very difficult to unravel, since different miRNAs can cooperate in the regulation of the same gene, and the same miRNA may regulate several genes. In addition, we must consider that currently the notion is widely accepted that many miRNAs act as fine-tuners of large gene networks rather than major genetic switches for specific signaling pathways or transcription factors [Martinez and Walhout, 2009; Han et al., 2015; Rajman and Schratt, 2017; Hurtado et al., $2018,2020]$. In this context, the action of miRNAs is to ensure that the expression of a large number of genes remains within a very narrow range, and therefore, it might

Non-Coding RNAs in Sexual

Development be futile to look for a single miRNA-mRNA interaction to explain the regulatory action of a miRNA during a critical developmental stage.

Finally, miRNAs may have unexpected ways of regulation and action during the gonadal sex determination process. For example, it was shown in the mouse that an inverted splicing event involving repeated sequences flanking Sry produces a circular RNA in germ cells that may act as a miRNA sponge for $m i R-138$ [Hansen et al., 2013]. Moreover, a recent study analyzed the global transcriptome profile of maternal blood plasma from pregnant heifers carrying either a male or a female embryo at a developmental stage coinciding with the peak of bovine $S R Y$ expression and found 56 differentially expressed miRNAs between both conditions [Sánchez et al., 2021]. The subsequent bioinformatic analysis revealed that "inflammatory" and "immune response" were among the biological processes regulated by the putative target genes of these miRNAs, indicating that they may be implicated in modulating the receptivity of the dam to a male embryo. In addition, they found that genes necessary for testis determination and differentiation, including $S R Y$ and SOX9, were also among the predicted targets of differentially expressed miRNAs, and the authors suggested that these miRNAs may play a role in testis differentiation and embryo masculinization [Sánchez et al., 2021].

\section{PIWI-Interacting RNAs}

piRNAs are 21-35 nucleotides long ncRNAs predominantly expressed in animals. They have been shown to be indispensable for fertility. They derive from single stranded RNAs, so they are independent from Dicer. Some piRNAs are derived from transposons and act as antisense RNAs, whereas others are derived from the $3^{\prime}$ UTR of mRNAs or from lncRNAs. In the later case, their biogenesis and function remain largely unknown. A fourth class include the so called $21 \mathrm{U}$ RNAs, which cooperate with $22 \mathrm{G}$ siRNAs to repress transcription of other genes via histone methylation, but they are specific to Caenorhabditis elegans [Han and Zamore, 2014]. The first piRNA to be identified was a silencer of Stellate in the testis of Drosophila melanogaster [Aravin et al., 2001].

In mammals, both piRNAs and PIWI proteins are mainly expressed in germ cells, where their main role is to act as transposon silencers. piRNA-mediated transposon repression protects the genome of germ cells from DNA damage, defects in gametogenesis, and subsequent infertility. They are transcribed from clusters located at 
specific loci and are processed into mature piRNAs that assemble with members of the PIWI family of Argonaute proteins to form piRNA-induced RNA silencing complexes (piRISCs). Upon assembly, they translocate to the nucleus and repress transposons by inducing heterochromatin formation at the target transposon loci [Sato and Siomi, 2020]. Whether this role is directly involved in fertility or not remains unknown. Zhang et al. [2015a] showed that piRNAs can also mediate the cleavage of specific mRNAs in mouse testes, so it would be interesting to study which piRNAs protect the genome against transposable elements and which of them are involved in a more direct regulation of gene expression in mammalian germ cell development. A different role in fertility has been described in C. elegans where it has been shown that the absence of piRNAs does not reduce fertility by transposon derepression but by epigenetic silencing of histone genes. In this case the downstream components of the piRNA pathway re-localize to histone mRNAs and synthezise small antisense RNAs (sRNAs) that induce silencing transgenerationally [Barucci et al., 2020].

After meiosis, the haploid round spermatids are differentiated into spermatozoa, a process known as spermiogenesis. At this stage, chromatin becomes highly compacted and transcription is gradually inhibited. Gene products that are needed during spermiogenesis are transcribed earlier and stored as translationally inert messenger ribonucleoproteins (mRNPs) until they are needed for translation. This uncoupling between transcription and translation is unique during spermiogenesis [Sassone-Corsi, 2002]. Some piRNAs involved in this process have been shown to be produced at meiotic stages as early as pachytene and induced by the transcription factor A-MYB [Li et al., 2013]. In the mouse, lack of the pachytene piRNA pi6 produce sperm with defects in capacitation and egg fertilization [Wu et al., 2020a]. The authors also showed that embryos heterozygous for pi6 have reduced viability in utero. Biochemical data suggest that pi6 cleaves mRNAs that encode proteins required for sperm function. This piRNA-mediated target repression requires base pairing between piRNAs and mRNA targets, slicer activity and the piRNA loading activity of MIWI (the mouse homologues of PIWI) [Zhang et al., 2015]. Besides this role of the MIWI/piRNA machinery in mRNA depletion during late spermiogenesis, MIWI/piRNA machinery is also responsible for activating translation of a subset of spermiogenic mRNAs, a process that permits coordination between protein synthesis and the morphological transformation into spermatozoa [Dai et al., 2019].

\section{Long Non-Coding RNAs}

lncRNAs represent the most diverse type of ncRNAs, as their length may vary from 200 to 100,000 nucleotides, with a median size of about 500 nt [Mattick and Rinn, 2015]. They are generally spliced as most of them contain 2-4 exons, although alternative splicing is not common [see Xu et al., 2019 and references therein]. Regarding their genomic location, lncRNAs can be classified into several categories: intergenic, intronic, antisense, bidirectional, promoter, and enhancer [Joshi and Rejender, 2020] (Fig. 2). Some of them are circular in structure [Hansen et al., 2013; Memczak et al., 2013] and may function as miRNA sponges [Panda, 2018]. Polyadenylation of lncRNAs is also frequent but not as much as in mRNAs. They are generally located in the nucleus in association with chromatin and its expression is more tissue-specific than that of mRNAs [Taylor et al., 2015]. They are generally subject to purifying selection, although structure rather than sequence may be under selection in some cases [Derrien et al., 2012; Smith et al., 2013]. IncRNAs regulate gene expression by several mechanisms, including binding to the promoters of target genes, inhibition of the RNA polymerase activity, and degradation of target mRNAs [Marchese et al., 2017; Taylor et al., 2015]. Testicular and neural tissues exhibit, in this order, the highest levels of expression of lncRNAs, compared to other tissues. Nevertheless, lncRNAs show, in general, low transcription levels, but expression is actively regulated, in particular in the case of ancient lncRNAs [Necsulea et al., 2014], indicating that they probably play important roles in testicular function, although most of them are probably still unknown. Despite this predominant expression in the testis, no study has demonstrated to date the involvement of lncRNAs in mammalian gonadal sex determination. Contrarily, they have been shown to have relevant roles in key stages of sexual development, including sex determination, in other vertebrates as well as in invertebrates. We will review as follows the functions of $\ln$ cRNAs in these processes.

\section{Role of IncRNAs in Mammalian Sex Differentiation}

Using RNA microarray technology, Chen et al. [2012] identified 56 lncRNAs showing higher expression in the developing ovary compared to the testis, and 26 more showing the opposite expression pattern in the mouse embryo from E11.5 to E14.5. Several lncRNAs have been shown to have a putative role in regulating genes necessary for testis or ovary development. This is the case for the pro-testicular factor SOX9. Smyk et al. [2013] found 


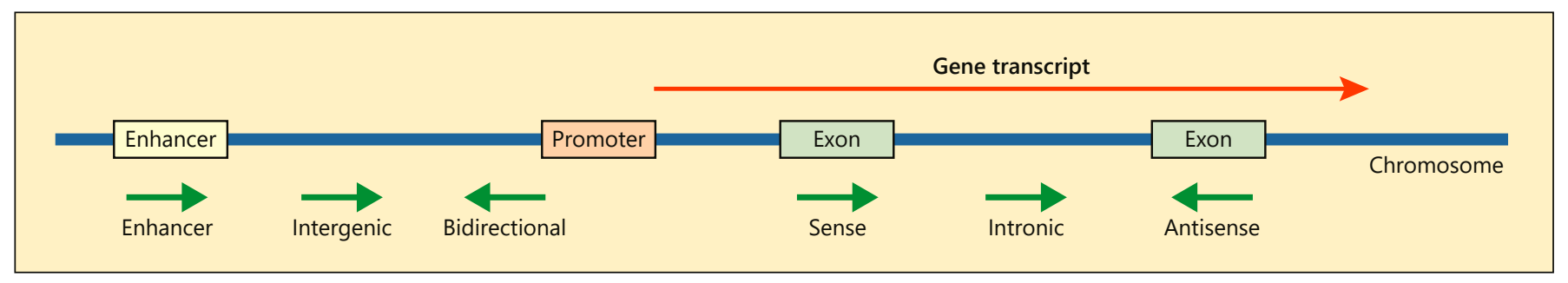

Fig. 2. Classification of lncRNA according to their genomic location.

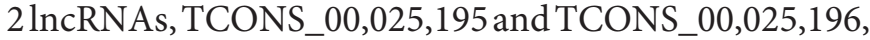
that were transcribed from a regulatory region, called RevSex, located on human chromosome 17, at long distance upstream of the SOX9 locus, that seems to contain a testis-specific enhancer [Benko et al., 2011]. Thus, these lncRNAs could have a role in the regulation of the testicular expression of SOX9 in humans [Rastetter et al., 2015], but this hypothesis has not yet been tested.

Like SOX9, DMRT1 (Doublesex and Mab-3 related transcription factor 1 ) is another regulatory protein with important roles in the male sexual development of many vertebrates [Herpin and Schartl, 2015]. A lncRNA transcribed from a locus in the mouse chromosome 5 was found to trans-splice with the Dmrt1 transcript (from chromosome 19) to generate a non-functional DMRT1 protein lacking the C-terminal end [Zhang et al., 2010]. The locus of this lncRNA, which was called Dmr (Dmrt1related ncRNA), contains 2 exons and produces 3 alternative transcripts of different lengths ( $D m r$ a, $775 \mathrm{bp} ; D m r$ b, $652 \mathrm{bp} ; \mathrm{Dmr}$ c, $748 \mathrm{bp}$ ). It is conserved in mouse and rat in a syntenic region shared between both species. However, the particular roles of these transcripts in the regulation of Dmrt1 expression are yet to be established.

The first functional circular RNA discovered in mammals is transcribed from the mouse Sry (sex determining region Y) [Capel et al., 1993]. As mentioned above, it was shown more recently that this circular lncRNA molecule contains 16 binding sites for $m i R-138$, and in vitro experiments have demonstrated that Sry circRNA (circSry) acts as a sponge for this specific miRNA [Hansen et al., 2013]. However, the possible involvement of both circSry and $m i R-138$ in mammalian gonadal sex determination is still to be elucidated.

\section{Role of IncRNAs in the Sex Differentiation of Non- \\ Mammalian Vertebrates}

The gene DMRT2, another member of the DMRT family, is also involved in sex determination and differ- entiation [Kim et al., 2003; Zhou et al., 2008; Yoshizawa et al., 2011]. A 537-nucleotide lncRNA, named DMRT2AS (dmrt2 antisense), was isolated and cloned from the gonads of the Chinese tongue sole, Cynoglossus semilaevis [Feng et al., 2021]. Its sequence is partially complementary to dmrt 2 on exon 4 and intron 3 , and is highly expressed in the developing testis of this fish. Using in vitro experiments, the authors showed that the presence of DMRT2-AS increased the transcription levels of $d m r t 2$, suggesting that DMRT2-AS is a transcriptional regulator of $d m r t 2$ and thus plays an important role in testis differentiation. Also, in another fish species, the tiger pufferfish Takifugu rubripes, high-throughput gonad transcriptome sequencing permitted to identify several lncRNAs predicted to be potential regulators of fish sex-related genes like $g s d f$ [Yan et al., 2021]. In the Chinese soft-shell turtle, Pelodiscus sinensis, gene expression analysis by RNA-seq led to the identification of a number of IncRNAs predicted to target sex differentiation-related protein-coding genes, including dmrt1, sox9, cyp 19a, sox3, and sox8, indicating that lncRNAs may have important roles in the regulation of the first steps of sex differentiation in this species [Zhang et al., 2018].

The chicken $\mathrm{Z}$ chromosome contains a locus (MHM) that is hypermethylated in male but not in female cells, which is transcribed into a lncRNA with potential roles in both localized dosage compensation and sex determination [Teranishi et al., 2001; Yang et al., 2010]. Functional studies have shown that misexpression of MHM induces asymmetric ovarian development in females and altered gonadal expression of the avian testis-determining gene $D M R T 1$, indicating that MHM plays an important role in chicken sex differentiation [Roeszler et al., 2012]. Interestingly, a window of MHM demethylation was found to coincide in time with key events in gonadal differentiation in the chicken [Yang et al., 2016]. The authors suggested that MHM transcripts may affect both testis and ovary differentiation by influencing sex-specific gene expression. 


\section{Role of $\ln$ RRNAs in Testis Function}

Apart from their roles in gonadal sex determination, sex differentiation, and gonad development, lncRNAs have been shown to have important roles in different aspects of testis function, including spermatogenesis, intratesticular immune response, and germ cell apoptosis as reviewed as follows.

\section{Spermatogenesis}

Spermatogenesis is the biological process of the testis most extensively studied regarding the regulatory action of lncRNAs. Some clues of the role of lncRNAs in the testis came from research that associated the expression of testis specific lncRNAs to particular cell types. The use of microarrays to profile lncRNAs expression in neonatal and adult mouse testes revealed that many lncRNAs where overlapping or located near genes coding for transcription factors involved in spermatogenesis, and epigenetic modifications similar to those present in protein coding genes suggested that their expression is tightly regulated [Sun et al., 2013]. These findings support the notion that lncRNAs have important roles in spermatogenesis. Regarding mammals, many microarray and RNA-seq studies were performed afterwards, mainly in the mouse, suggesting that lncRNAs have important an diverse regulatory roles in all stages of spermatogenesis. Also, functional studies have been performed validating previous predictive analyzes and clarifying the mode of action of particular lncRNAs. This has been extensively reviewed in recent years [Joshi and Rejender, 2020; Sahlu et al., 2020], so here we will just look over some of the more relevant cases.

The Prss/Tessp gene cluster is activated in the primary spermatocytes at the late pachytene stage and is necessary for meiotic progression. Two lncRNAs have been described at the Prss/Tessp locus, located on mouse chromosome 9. These are lncRNA-HSVIII [Yoneda et al., 2016] and Tesra [Satoh et al., 2019]. The later significantly increased Prss42/Tessp- 2 promoter activity in germ cells by direct binding to the promoter region, as demonstrated by ChIRP assay. The molecular mechanism by which Tesra enhances the activity of Prss/Tessp gene promoter remains unknown.

Taurine upregulated gene 1 (Tug1) is a lncRNA expressed in several embryonic and adult tissues in both human and mouse. Its locus is located on mouse chromosome 11 and its sequence is one of the better conserved between mouse and humans [Lewandowski et al., 2020]. Tug1-knockout male mice are sterile, showing oligospermia and abnormal sperm morphology, evidencing an essential role for this lncRNA in male fertility.
As mentioned above, $D m r$ is a lncRNA that transsplices with the Dmrt1 transcript and generates a nonfunctional DMRT1 protein, which is relevant for testis development [Zhang et al., 2010]. However, DMRT1 also plays important roles in the germ line of the testis, where it upregulates Sohlh1 (spermatogenesis and oogenesis specific basic helix-loop-helix 1 gene) and prevents early meiosis of spermatogonia by repressing Stra 8 (stimulated by retinoic acid 8 gene) [Matson et al., 2010]. Therefore, the regulatory action of $\mathrm{Dmr}$ could play an important role in the spermatogonial transition between mitosis and meiosis.

Over-expression of NLC1-C (narcolepsy candidateregion 1 gene), a lncRNA expressed in the cytoplasm of human spermatogonia and early spermatocytes, induced cell proliferation, whereas its loss promoted apoptosis [Lü et al., 2015]. The authors also reported that NLC1-C expression was reduced in MA (maturation arrest) patients and that this lncRNA inhibited the transcription of $m i R-320 a$ and $m i R-383$ by interacting with the nucleolin RNA-binding domain.

\section{Dosage Compensation}

The sex chromosome system of mammals implies that around 1,000 of X-linked genes are in double dosage in females (XX) compared with males (XY). These gene dosage differences between males and females need to be compensated, a problem that in mammals was evolutionary solved by the inactivation of 1 of the $2 \mathrm{X}$ chromosomes of females. The $\mathrm{Y}$ chromosome is almost a genetic desert, so no dosage compensation is required for the few Y-linked genes. The process of mammalian X chromosome inactivation (XCI) depends on an X-linked locus that produces a lncRNA. This X-linked X-inactive-specific transcript (Xist) was one of the first functional lncRNAs to be discovered in the early 1990s, and even today, 30 years later, many aspects of its molecular mechanisms of action remain unclear. The role of Xist in XCI has been the subject of dozens of comprehensive reviews in the last years [see Brockdorff et al., 2020; Monfort and Wutz, 2020]. XCI initiates early during development by the spreading in cis of the Xist transcript across the X chromosome from which it is transcribed. During XCI, Xist RNA drives 3 important processes: (1) a wave of gene silencing, (2) recruitment of multiple chromatin-modifying factors, and (3) a major structural reorganization giving rise to complete heterochromatinization of the inactive $\mathrm{X}$ chromosome, which thus becomes a Barr body (lyonization) [Lyon, 1961]. In other species with XX/XY sex chromosomes, like D. melanogaster, the male X func- 
tions at double transcriptional intensity than the 2 active $\mathrm{X}$ chromosomes of the female. This process is controlled by an evolutionarily conserved chromatin-modifying machine called the MSL complex (for male-specific lethal complex), whose assembly and spreading to active genes along the X chromosome depends on 2 lncRNAs, roX1 and roX2 [Lucchesi and Kuroda, 2015].

\section{Steroidogenesis}

Start (steroidogenesis activating $\operatorname{lncRNA}$ in testis) is a lncRNA with a regulatory role in the testis. It is Leydig specific and may regulate steroidogenesis [Otsuka et al., 2021]. CRISPR/Cas9-generated Start knockout (KO) mice showed an increased expression of genes involved in steroidogenesis, such as Star and Hsd3b1, as demonstrated by RNA-seq and RT-qPCR.

Another lncRNA with the capability to regulate steroidogenesis is SRA (steroid receptor RNA activator). The SRA locus is intergenic and produces a core sequence of $687 \mathrm{nt}$ in humans. The SRA transcript acts as a coactivator of steroid receptors, including the androgen receptor (AR), estrogen receptor (ER), glucocorticoid receptor (GR), and progesterone receptor (PR) [Lanz et al., 1999]. In addition to steroidogenesis, SRA is known to be involved in many other physiological and pathological processes, including mammary gland development, myocyte and adipocyte differentiation, tumorigenesis, hepatic steatosis, and stem cell function [Sheng et al., 2018].

Misregulation of a number of lncRNAs, including corticotropin releasing hormone binding protein $(C R H B P)$, plasmacytoma variant translocation 1 (PVT1), and HLA Complex Group 26 (HCG26) have been shown to cause hyperandrogenism in polycystic ovary syndrome (PCOS) patients, evidencing their capability to influence the metabolism and synthesis of androgens [Lee et al., 2016; Liu et al., 2017, 2020].

\section{Immune Response}

Kurihara et al. [2014] described a bidirectional spermatocyte-specific enhancer, CNS-1, controlling the expression of the mouse Tcam1 gene that encodes a celladhesion protein. In the opposite direction, this enhancer also activates the expression of the Smarcd2 gene, involved in chromatin regulation, and a $2.4-\mathrm{kb} \ln \mathrm{RNA}$

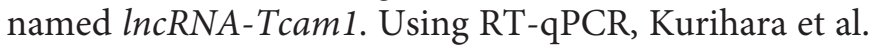
[2017] showed a higher expression level of lncRNATcam 1 between days 7 and 14 after birth, a pattern that correlated with 21 protein-coding genes. A more detailed analysis showed that 6 of these genes are potentially acti-

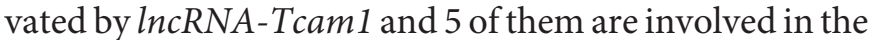

immune response. The authors proposed that $\ln R N A$ Tcam 1 may regulate the innate immune response by controlling the interferon-responsive genes during meiosis. It is interesting to point out that the testis is subjected to an attenuated immunological environment known as "immune privilege", that prevents autoimmune attack against germ cells and implies both a diminished capability of the testicular macrophage population to mount an inflammatory response and the constitutive expression of anti-inflammatory cytokines by immune and other somatic cells [Fijak and Meinhardt, 2006; Li et al., 2012; Zhao et al., 2014]. Hence, the possible role of $\operatorname{lncRNA-}$ Tcam1 as a regulator of the intratesticular immune response could be crucial for the preservation of the adult germ cell lineage and normal testis function.

\section{Apoptosis}

The lncRNA LOC102551356 has been associated to apoptosis induced by nickel nanoparticles in cocultures of Sertoli-germ cells [Kong et al., 2019a]. This lncRNA targets the genes Igfbp 3 in the $\mathrm{p} 53$ signaling pathway and Bax, Bcl-2, Caspase3, and Caspase9 in the mitochondrial apoptotic pathway.

\section{Concluding Remarks and Perspectives}

The conceptual idea of the RNA world put the RNA in the very origin of life. It explains not only the classical processes of the central dogma of molecular biology in which mRNAs, rRNAs, and tRNAs collaborate for protein synthesis, or others like splicing or telomere building, but also the existence of many types of ncRNAs that can be involved in processes such as the regulation of gene expression, epigenetics, chromatin remodeling, etc. Being the testis the organ with the higher variety of ncRNA expression, it would not escape to all sort of processes with fundamental roles being regulated or modulated by one or more of these RNAs. A whole new biology is taking off before us.

We still miss the big picture and the tools to its discovery. Most profiling studies are limited to an overall picture, providing lists of ncRNAs associated with different cell types or processes. In the testis, most of the ncRNAs studied have been involved in spermatogenesis. The number of studies focusing on the role of particular ncRNAs, albeit growing, is still insufficient. Single-cell studies are able to provide big amount of data but the analyses of big data combined with complex interactions are difficult to assess by conventional tools. This combi- 
nation, however, is the typical breeding ground for deep learning [Alam et al., 2020]. For instance, convolutional neural networks are being used for ncRNA classification [Aoki and Sakakibara, 2018; Amin et al., 2019; Chantsalnyam et al., 2020] and lncRNA identification [Baek et al., 2018; Liu et al., 2019] that significantly outperform other available methods. More complex networks are currently being developed that may help not only to classify ncRNAs but also to discover their modes of action. Song et al. [2020] developed a complex framework involving capsule, a recurrent and long-short-term memory network to analyze interactions between lncRNAs and miRNAs. The method has proven to be generalizable after testing with several datasets. A deep learning tool for the analysis of ncRNA-protein interactions has also been developed [Peng et al., 2019]. Other approaches that rely on the secondary structure to predict functions [Ramakrishnaiah et al., 2021] are computationally intensive, but deep learning has also provided a way to predict the function of sncRNAs from raw sequence data [Noviello et al., 2020], providing more robust results than methods based on secondary structure and at a fraction of the computational cost.

\section{Conflict of Interest Statement}

The authors have no conflicts of interest to declare.

\section{Funding Sources}

This research was funded by the Andalusian Government, Junta de Andalucía with FEDER funds, grants numbers A-BIO106-UGR18 and BIO109.

\section{Author Contributions}

M.B. wrote a first short draft of the manuscript and A.H., R.J., and F.J.B. completed it. M.B. and R.J. prepared the figures. A.H. and F.J.B. prepared the tables. All authors revised the final version of the manuscript.

\section{References}

Alam T, Al-Absi HRH, Schmeier S. Deep learning in lncRNAome: Contribution, challenges, and, perspectives. Noncoding RNA. 2020;6: 47.

Amin N, McGrath A, Chen Y-PP. Evaluation of deep learning in non-coding RNA classification. Nat Mach Intell. 2019;1(5):246-56.

Aoki G, Sakakibara Y. Convolutional neural networks for classification of alignments of noncoding RNA sequences. Bioinformatics. 2018; 34:i237-44.

Aravin AA, Naumova NM, Tulin AV, Vagin VV, Rozovsky YM, Gvozdev VA. Double-stranded RNA-mediated silencing of genomic tandem repeats, transposable elements in the $\mathrm{D}$. melanogaster germline. Curr Biol. 2001;11: 1017-27.

Baek J, Lee B, Kwon S, Yoon S. LncRNAnet: long non-coding RNA identification using deep learning. Bioinformatics. 2018;34:3889-97.

Bai M, Sun L, Jia C, Li J, Han Y, Liu H, et al. Integrated analysis of miRNA and mRNA expression profiles reveals functional miRNA-targets in development testes of small tail han sheep. G3 (Bethesda). 2019;9:523-33.

Barucci G, Cornes E, Singh M, Li B, Ugolini M, Samolygo A, et al. Small-RNA-mediated transgenerational silencing of histone genes impairs fertility in piRNA mutants. Nat Cell Biol. 2020;22:235-45.

Benko S, Gordon CT, Mallet D, Sreenivasan R, Thauvin-Robinet C, Brendehaug A, et al. Disruption of a long distance regulatory region upstream of SOX9 in isolated disorders of sex development. J Med Genet. 2011;48:825-30.
Bernstein E, Kim SY, Carmell MA, Murchison EP, Alcorn H, Li MZ, et al. Dicer is essential for mouse development. Nat Genet. 2003;35: 215-7.

Brockdorff N, Bowness JS, Wei G. Progress toward understanding chromosome silencing by Xist RNA. Genes Dev. 2020;34:733-44.

Buchold GM, Coarfa C, Kim J, Milosavljevic A, Gunaratne PH, Matzuk MM. Analysis of microRNA expression in the prepubertal testis. PLoS One. 2010;5:e15317.

Bushati N, Cohen SM. microRNA functions. Annu Rev Cell Dev Biol. 2007;23:175-205.

Cabili MN, Trapnell C, Goff L, Koziol M, TazonVega B, Regev A, et al. Integrative annotation of human large intergenic noncoding RNAs reveals global properties and specific subclasses. Genes Dev. 2011;25:1915-27.

Capel B, Swain A, Nicolis S, Hacker A, Walter M, Koopman $\mathrm{P}$, et al. Circular transcripts of the testis-determining gene Sry in adult mouse testis. Cell. 1993;73:1019-30.

Carré GA, Greenfield A.The gonadal supporting cell lineage, mammalian sex determination: The differentiation of Sertoli and granulosa cells. Results Probl Cell Differ. 2016;58:47-66.

Carthew RW, Sontheimer EJ. Origins and mechanisms of miRNAs and siRNAs. Cell. 2009;136: 642-55.

Chantsalnyam T, Lim DY, Tayara H, Chong KT. ncRDeep: Non-coding RNA classification with convolutional neural network. Comput Biol Chem. 2020;88:107364.
Cheloufi S, Dos Santos CO, Chong MM, Hannon GJ. A dicer-independent miRNA biogenesis pathway that requires Ago catalysis. Nature. 2010;465(7298):584-9.

Chen H, Palmer JS, Thiagarajan RD, Dinger ME, Lesieur $\mathrm{E}$, Chiu $\mathrm{H}$, et al. Identification of novel markers of mouse fetal ovary development. PLoS One. 2012;7(7):e41683.

Cheng LC, Pastrana E, Tavazoie M, Doetsch F. miR-124 regulates adult neurogenesis in the subventricular zone stem cell niche. Nat Neurosci. 2009;12:399-408.

Chong MM, Zhang G, Cheloufi S, Neubert TA, Hannon GJ, Littman DR. Canonical and alternate functions of the microRNA biogenesis machinery. Genes Dev. 2010;24:1951-60.

Cifuentes D, Xue H, Taylor DW, Patnode H, Mishima Y, Cheloufi S, et al. A novel miRNA processing pathway independent of Dicer requires Argonaute2 catalytic activity. Science. 2010;328(5986):1694-8.

Colvin JS, Green RP, Schmahl J, Capel B, Ornitz DM. Male-to-female sex reversal in mice lacking fibroblast growth factor 9. Cell. 2001;104:875-89.

Cui S, Liu Z, Tao B, Fan S, Pu Y, Meng X, et al. miR-145 attenuates cardiac fibrosis through the AKT/GSK- $3 \beta / \beta$-catenin signaling pathway by directly targeting SOX9 in fibroblasts. J Cell Biochem. 2021;122(2):209-21.

Dai A, Sun H, Fang T, Zhang Q, Wu S, Jiang Y, et al. MicroRNA-133b stimulates ovarian estradiol synthesis by targeting Foxl2. FEBS Lett. 2013;587:2474-82. 
Dai P, Wang X, Gou LT, Li ZT, Wen Z, Chen ZG, et al. A translation-activating function of MIWI/piRNA during mouse spermiogenesis. Cell. 2019;179:1566-e16.

Derrien T, Johnson R, Bussotti G, Tanzer A, Djebali S, Tilgner $\mathrm{H}$, et al. The gencode v7 catalog of human long noncoding RNAs: analysis of their gene structure, evolution, and expression. Genome Res. 2012;22:1775-89.

Ding H, Liu M, Zhou C, You X, Su T, et al. Integrated analysis of miRNA and mRNA expression profiles in testes of Duroc and Meishan boars. BMC Genomics. 2020;21:686-11.

Ding R, Liu X, Zhang J, Yuan J, Zheng S, Cheng $\mathrm{X}$, et al. MiR-1-3p downregulation delays endochondral ossification of the acetabular roof in DDH. J Orthop Surg Res. 2021;16:512.

Feng B, Li S, Wang Q, Tang L, Huang F, Zhang Z, et al. lncRNA DMRT2-as acts as a transcriptional regulator of dmrt2 involving in sex differentiation in the chinese tongue sol (Cynoglossus semilaevis). Comp Biochem Physiol B Biochem Mol Biol. 2021;253:110542.

Fernández-Pérez D, Brieño-Enríquez MA, IsolerAlcaraz J, Larriba E, Mazo JD. MicroRNA: dynamics at the onset of primordial germ, somatic cell sex differentiation during mouse embryonic gonad development. RNA. 2018; 24:287-303.

Fijak M, Meinhardt A. The testis in immune privilege. Immunol Rev. 2006;213:66-81.

Flynn RA, Pedram K, Malaker SA, Batista PJ, Smith BAH, Johnson AG, et al. Small RNAs are modified with $\mathrm{N}$-glycans, displayed on the surface of living cells. Cell. 2021;184:3109-24. e22.

Ganesan G, Rao SM. A novel noncoding RNA processed by Drosha is restricted to nucleus in mouse. RNA. 2008;14:1399-410.

Ha M, Kim VN. Regulation of microRNA biogenesis. Nat Rev Mol Cell Biol. 2014;15:509-24.

Han BW, Zamore PD. piRNAs. Curr Biol. 2014; 24(16):R730-3.

Han YC, Vidigal JA, Mu P, Yao E, Singh I, González AJ, et al. An allelic series of miR-17 92-mutant mice uncovers functional specialization and cooperation among members of a microRNA polycistron. Nat Genet. 2015; 47:766-75.

Hansen TB, Jensen TI, Clausen BH, Bramsen JB, Finsen B, Damgaard CK, et al. Natural RNA circles function as efficient microRNA sponges. Nature. 2013;495:384-8.

Hayashi K, Chuva de Sousa Lopes SM, Kaneda M, Tang F, Hajkova P, Lao K, et al. MicroRNA biogenesis is required for mouse primordial germ cell development and spermatogenesis. PLoS One. 2008;3:e1738.

Herpin A, Schartl M. Plasticity of gene-regulatory networks controlling sex determination: of masters, slaves, usual suspects, newcomers, and usurpators. EMBO Rep. 2015;16:1260-74.

Hu B, Wang J, Jin X. MicroRNA-138 suppresses cell proliferation and invasion of renal cell carcinoma by directly targeting SOX9. Oncol Lett. 2017;14:7583-8.
Huang CC, Yao HH. Inactivation of Dicer1 in Steroidogenic factor 1-positive cells reveals tissue-specific requirement for Dicer1 in adrenal, testis, and ovary. BMC Dev Biol. 2010;10: 66-10.

Huang C-CJ, Parker KL, Yao HHC. Ablation of Dicer in somatic cells of fetal testes leads to postnatal testis dysgenesis in mice. Biol Reprod. 2009;81(Suppl_1):37.

Hurtado A, Real FM, Palomino R, Carmona FD, Burgos M, Jiménez R, et al. Sertoli cell-specific ablation of miR-17-92 cluster significantly alters whole testis transcriptome without apparent phenotypic effects. PLoS One. 2018;13: e0197685.

Hurtado A, Palomino R, Georg I, Lao M, Real FM, Carmona FD, et al. Deficiency of the oncomiRNA cluster, miR-106b 25, causes oligozoospermia and the cooperative action of miR-106b 25 and miR-17 92 is required to maintain male fertility. Mol Hum Reprod. 2020;26(6):389-401.

Joshi M, Rajender S. Long non-coding RNA (lncRNAs) in spermatogenesis, male infertility. Reprod Biol Endocrinol. 2020;18:103.

Kapranov P, Cheng J, Dike S, Nix DA, Duttagupta R, Willingham AT, et al. RNA maps reveal new RNA classes and a possible function for pervasive transcription. Science. 2007;316: 1484-8.

Kashimada K, Pelosi E, Chen H, Schlessinger D, Wilhelm D, Koopman P. FOXL2 and BMP2 act cooperatively to regulate follistatin gene expression during ovarian development. Endocrinology. 2011;152:272-80.

Kasimanickam VR, Kasimanickam RK. Differential expression of microRNAs in sexually immature and mature canine testes. Theriogenology. 2015;83:394-e1.

Kim S, Kettlewell JR, Anderson RC, Bardwell VJ, Zarkower D. Sexually dimorphic expression of multiple doublesex-related genes in the embryonic mouse gonad. Gene Expr Patterns. 2003;3:77-82.

Kim VN, Han J, Siomi MC. Biogenesis of small RNAs in animals. Nat Rev Mol Cell Biol. 2009; 10:126-39.

Kim GJ, Georg I, Scherthan H, Merkenschlager M, Guillou F, Scherer G, et al. Dicer is required for Sertoli cell function and survival. Int J Dev Biol. 2010;54:867-75.

Kong L, Hu W, Gao X, Wu Y, Xue Y, Cheng K, et al. Molecular mechanisms underlying nickel nanoparticle induced rat Sertoli-germ cells apoptosis. Sci Total Environ. 2019a;692:2408

Kong X, Zhao Y, Li X, Tao Z, Hou M, Ma H. Overexpression of HIF-2 $\alpha$-dependent NEAT1 promotes the progression of non-small cell lung cancer through miR-101-3p/SOX9/ Wnt/ $\beta$-catenin signal pathway. Cell Physiol Biochem. 2019b;52:368-81.

Korhonen HM, Meikar O, Yadav RP, Papaioannou MD, Romero Y, Da Ros M, et al. Dicer is required for haploid male germ cell differentiation in mice. PLoS One. 2011;6:e24821.
Kurihara M, Shiraishi A, Satake H, Kimura AP. A conserved noncoding sequence can function as a spermatocyte-specific enhancer and a bidirectional promoter for a ubiquitously expressed gene and a testis-specific long noncoding RNA. J Mol Biol. 2014;426:3069-93.

Kurihara M, Otsuka K, Matsubara S, Shiraishi A, Satake H, Kimura AP. A testis-specific long non-coding RNA, lncRNA-Tcam1, regulates immune-related genes in mouse male germ cells. Front Endocrinol (Lausanne). 2017;8 299.

Lanz RB, McKenna NJ, Onate SA, Albrecht U, Wong J, Tsai SY, et al. A steroid receptor coactivator, SRA, functions as an RNA and is present in an SRC-1 complex. Cell. 1999;97: $17-27$.

Lee YS, Lewis JA, Ippolito DL, Hussainzada N, Lein PJ, Jackson DA, et al. Repeated exposure to neurotoxic levels of chlorpyrifos alters hippocampal expression of neurotrophins and neuropeptides. Toxicology. 2016;340:53-62.

Lei L, Jin S, Gonzalez G, Behringer RR, Woodruff TK. The regulatory role of Dicer in folliculogenesis in mice. Mol Cell Endocrinol. 2010; 315:63-73.

Lewandowski JP, Dumbović G, Watson AR, Hwang T, Jacobs-Palmer E, Chang N, et al. The tug 1 lncRNA locus is essential for male fertility. Genome Biol. 2020;21:237.

Li N, Wang T. Han D: Structural, cellular, molecular aspects of immune privilege in the testis. Front Immunol. 2012;3:152.

Li XZ, Roy CK, Dong X, Bolcun-Filas E, Wang J, Han BW, et al. An ancient transcription factor initiates the burst of piRNA production during early meiosis in mouse testes. Mol Cell. 2013;50:67-81.

Li B, Liu D, Yang P, Li HY, Wang D. miR-613 inhibits liver cancer stem cell expansion by regulating SOX9 pathway. Gene. 2019;707:7885.

Li X, Lv F, Li F, Du M, Liang Y, Ju S, et al. Long Non-coding RNA H19 facilitates small cell lung cancer tumorigenesis through miR-1405p/FGF9 axis. Onco Targets Ther. 2020;13: 3525-34.

Lian C, Sun B, Niu S, Yang R, Liu B, Lu C, et al. A comparative profile of the microRNA transcriptome in immature and mature porcine testes using Solexa deep sequencing. FEBS J. 2012;279:964-75.

Liang H, Luo R, Chen X, Zhao Y, Tan A. miR-187 inhibits the growth of cervical cancer cells by targeting FGF9. Oncol Rep. 2017;38:1977-84.

Liang Z, Xu J, Ma Z, Li G, Zhu W. MiR-187 suppresses non-small-cell lung cancer cell proliferation by targeting FGF9. Bioengineered. 2020;11:70-80.

Lin YT, Capel B. Cell fate commitment during mammalian sex determination. Curr Opin Genet Dev. 2015;32:144-52.

Lin RX, Zhan GF, Wu JC, Fang H, Yang SL. LncRNA SNHG14 sponges miR-206 to affect proliferation, apoptosis, metastasis of hepatocellular carcinoma cells by regulating SOX9. Dig Dis Sci. 2021. 
Liu Y, Zhang W, Liu K, Liu S, Ji B, Wang Y. miR138 suppresses cell proliferation and invasion by inhibiting SOX9 in hepatocellular carcinoma. Am J Transl Res. 2016;8:2159-68.

Liu YD, Li Y, Feng SX, Ye DS, Chen X, Zhou XY, et al. Long noncoding RNAs: potential regulators involved in the pathogenesis of polycystic ovary syndrome. Endocrinology. 2017;158: 3890-9.

Liu XQ, Li BX, Zeng GR, Liu QY, Ai DM. Prediction of long non-coding RNAs based on deep learning. Genes (Basel). 2019;10:273.

Liu G, Liu S, Xing G, Wang F. IncRNA PVT1/ MicroRNA-17-5p/PTEN axis regulates secretion of E2 and P4, proliferation, and apoptosis of ovarian granulosa cells in PCOS. Mol Ther Nucleic Acids. 2020;20:205-16.

Lü M, Tian H, Cao YX, He X, Chen L, Song X, et al. Downregulation of mir-320a/383-spongelike long non-coding RNA nlc1- (narcolepsy candidate-region 1 genes) is associated with male infertility and promotes testicular embryonal carcinoma cell proliferation. Cell Death Dis. 2015;6:e1960.

Lucchesi JC, Kuroda MI. Dosage compensation in Drosophila. Cold Spring Harb Perspect Biol. 2015;7:a019398.

Luo Y, Wu X, Ling Z, Yuan L, Cheng Y, Chen J, et al. microRNA133a targets Foxl2 and promotes differentiation of $\mathrm{C} 2 \mathrm{C} 12$ into myogenic progenitor cells. DNA Cell Biol. 2015;34: 29-36.

Luo J, Han J, Li Y, Liu Y. Downregulated SOX9 mediated by miR-206 promoted cell apoptosis in Legg-Calvé-Perthes disease. Oncol Lett. 2018;15:1319-24.

Luo H, Chen B, Weng B, Tang X, Chen Y, Yang A, et al. miR-130a promotes immature porcine Sertoli cell growth by activating SMAD5 through the TGF- $\beta$-PI3K/AKT signaling pathway. FASEB J. 2020;34:15164-79.

Lyon MF. Gene action in the X-chromosome of the mouse (Mus musculus L.). Nature. 1961; 190: $372-3$. $10.1038 / 190372 \mathrm{a} 0$.

http: //dx.doi.org:

Maatouk DM, Loveland KL, McManus MT, Moore K, Harfe BD. Dicer1 is required for differentiation of the mouse male germline. Biol Reprod. 2008;79:696-703.

Marchese FP, Raimondi I, Huarte M. The multidimensional mechanisms of long noncoding RNA function. Genome Biol. 2017;18:206.

Martinez NJ, Walhout AJ. The interplay between transcription factors and microRNAs in genome-scale regulatory networks. BioEssays. 2009;31:435-45.

Martinez-Sanchez A, Dudek KA, Murphy CL. Regulation of human chondrocyte function through direct inhibition of cartilage master regulator SOX9 by microRNA-145 (miRNA-145). J Biol Chem. 2012;287:916-24.

Matson CK, Murphy MW, Griswold MD, Yoshida S, Bardwell VJ, Zarkower D. The mammalian doublesex homolog DMRT1 is a transcriptional gatekeeper that controls the mitosis versus meiosis decision in male germ cells. Dev Cell. 2010;19:612-24.
Mattick JS, Rinn JL. Discovery and annotation of long noncoding RNAs. Nat Struct Mol Biol. 2015;22:5-7.

Memczak S, Jens M, Elefsinioti A, Torti F, Krueger J, Rybak A, et al. Circular RNAs are a large class of animal RNAs with regulatory potency. Nature. 2013;495:333-8.

Mishima T, Takizawa T, Luo SS, Ishibashi O, Kawahigashi Y, Mizuguchi Y, et al. MicroRNA (miRNA) cloning analysis reveals sex differences in miRNA expression profiles between adult mouse testis and ovary. Reproduction. 2008;136:811-22.

Miyawaki S, Tachibana M. Role of epigenetic regulation in mammalian sex determination. Curr Top Dev Biol. 2019;134:195-221.

Monfort A, Wutz A. The B-side of Xist. F1000Res. 2020;9:55.

Murchison EP, Stein P, Xuan Z, Pan H, Zhang MQ, Schultz RM, et al. Critical roles for Dicer in the female germline. Genes Dev. 2007;21: 682-93.

Nagaraja AK, Andreu-Vieyra C, Franco HL, Ma L, Chen R, Han DY, et al. Deletion of Dicer in somatic cells of the female reproductive tract causes sterility. Mol Endocrinol. 2008;22: 2336-52.

Necsulea A, Soumillon M, Warnefors M, Liechti A, Daish T, Zeller U, et al. The evolution of lncRNA repertoires and expression patterns in tetrapods. Nature. 2014;505:635-40.

Noviello TMR, Ceccarelli F, Ceccarelli M, Cerulo L. Deep learning predicts short non-coding RNA functions from only raw sequence data. PLoS Comput Biol. 2020;16:e1008415.

O'Brien J, Hayder H, Zayed Y, Peng C. Overview of microRNA biogenesis, mechanisms of actions, and circulation. Front Endocrinol (Lausanne). 2018;9:402.

Otsuka K, Matsubara S, Shiraishi A, Takei N, Satoh $\mathrm{Y}$, Terao $\mathrm{M}$, et al. A testis-specific long noncoding RNA, Start, is a regulator of steroidogenesis in mouse Leydig cells. Front Endocrinol (Lausanne). 2021;12:665874.

Panda AC. Circular RNAs act as miRNA sponges. Adv Exp Med Biol. 2018;1087:67-79.

Papaioannou MD, Pitetti JL, Ro S, Park C, Aubry F, Schaad O, et al. Sertoli cell Dicer is essential for spermatogenesis in mice. Dev Biol. 2009; 326:250-9.

Peng C, Han S, Zhang H, Li Y. RPITER: A hierarchical deep learning framework for ncRNAprotein interaction prediction. Int J Mol Sci. 2019;20:1070.

Rajman M, Schratt G. MicroRNAs in neural development: from master regulators to finetuners. Development. 2017;144:2310-22.

Rakoczy J, Fernandez-Valverde SL, Glazov EA, Wainwright EN, Sato T, Takada S, et al. MicroRNAs-140-5p/140-3p modulate Leydig cell numbers in the developing mouse testis. Biol Reprod. 2013;88:143.

Ramakrishnaiah Y, Kuhlmann L, Tyagi S. linc2function: A deep learning model to identify and assign function to long noncoding RNA (lncRNA). bioRxiv. 2021. 2021.01.29.428785.
Ran M, Chen B, Wu M, Liu X, He C, Yang A, et al. Integrated analysis of miRNA and mRNA expression profiles in development of porcine testes. RSC Adv. 2015;5(78):63439-49.

Rani SB, Rathod SS, Karthik S, Kaur N, Muzumdar D, Shiras AS. MiR-145 functions as a tumor-suppressive RNA by targeting Sox 9 and adducin 3 in human glioma cells. Neuro Oncol. 2013;15:1302-16.

Rastetter RH, Smith CA, Wilhelm D. The role of non-coding RNAs in male sex determination and differentiation. Reproduction. 2015;150: R93-107.

Ravasi T, Suzuki H, Pang KC, Katayama S, Furuno $\mathrm{M}$, Okunishi R, et al. Experimental validation of the regulated expression of large numbers of non-coding RNAs from the mouse genome. Genome Res. 2006;16:11-9.

Real FM, Sekido R, Lupiáñez DG, Lovell-Badge R, Jiménez R, Burgos M. A microRNA (mmumir-124) prevents Sox9 expression in developing mouse ovarian cells. Biol Reprod. 2013; 89:78.

Ro S, Park C, Sanders KM, McCarrey JR, Yan W. Cloning and expression profiling of testis-expressed microRNAs. Dev Biol. 2007;311:592602.

Roeszler KN, Itman C, Sinclair AH, Smith CA. The long non-coding RNA, MHM, plays a role in chicken embryonic development, including gonadogenesis. Dev Biol. 2012;366: $317-26$.

Ruby JG, Jan CH, Bartel DP. Intronic microRNA precursors that bypass Drosha processing. Nature. 2007;448(7149):83-6.

Sahlu BW, Zhao S, Wang X, Umer S, Zou H, Huang J, et al. Long noncoding RNAs: new insights in modulating mammalian spermatogenesis. J Anim Sci Biotechnol. 2020;11: 16.

Sánchez JM, Gómez-Redondo I, Browne JA, Planells B, Gutiérrez-Adán A, Lonergan $\mathrm{P}$. MicroRNAs in amniotic fluid, maternal blood plasma associated with sex determination, early gonad differentiation in cattle. Biol Reprod. 2021;105(2):345-58.

Sang Q, Liu X, Sun D. Role of miR-613 as a tumor suppressor in glioma cells by targeting SOX9. Onco Targets Ther. 2018;11:2429-38.

Sanuki R, Onishi A, Koike C, Muramatsu R, Watanabe S, Muranishi Y, et al. miR-124a is required for hippocampal axogenesis and retinal cone survival through Lhx2 suppression. Nat Neurosci. 2011;14:1125-34.

Sassone-Corsi P. Unique chromatin remodeling and transcriptional regulation in spermatogenesis. Science. 2002;296:2176-8.

Sato K, Siomi MC. The piRNA pathway in Drosophila ovarian germ and somatic cells. Proc Jpn Acad Ser B Phys Biol Sci. 2020;96:32-42.

Satoh Y, Takei N, Kawamura S, Takahashi N, Kotani T, Kimura AP. A novel testis-specific long noncoding RNA, Tesra, activates the Prss42/Tessp-2 gene during mouse spermatogenesis†. Biol Reprod. 2019;100:83348. 
Seal RL, Chen LL, Griffiths-Jones S, Lowe TM, Mathews MB, O'Reilly D, et al. A guide to naming human non-coding RNA genes. EMBO J. 2020;39:e103777.

She ZY, Yang WX. Sry and SoxE: genes: How they participate in mammalian sex determination and gonadal development? Semin Cell Dev Biol. 2017;63:13-22.

Sheng L, Ye L, Zhang D, Cawthorn WP, Xu B. New insights into the long non-coding RNA SRA: Physiological functions and mechanisms of action. Front Med (Lausanne). 2018; $5: 244$.

Smith MA, Gesell T, Stadler PF, Mattick JS. Widespread purifying selection on RNA structure in mammals. Nucleic Acids Res. 2013;41: 8220-36.

Smyk M, Szafranski P, Startek M, Gambin A, Stankiewicz P. Chromosome conformation capture-on-chip analysis of long-range cisinteractions of the SOX9 promoter. Chromosome Res. 2013;21:781-8.

Song R, Ro S, Michaels JD, Park C, McCarrey JR, Yan W. Many X-linked microRNAs escape meiotic sex chromosome inactivation. Nat Genet. 2009;41:488-93.

Song J, Tian S, Yu L, Yang Q, Xing Y, Zhang C, et al. MD-MLI: Prediction of miRNA-lncRNA interaction by using multiple features, hierarchical deep learning. IEEE/ACM Trans Comput Biol Bioinform.2020; available at http:// dx.doi.org/10.1109/TCBB.2020.3034922.

Sun J, Lin Y, Wu J. Long non-coding RNA expression profiling of mouse testis during postnatal development. PLoS One. 2013;8:e75750.

Sun T, Liu Z, Zhang R, Ma S, Lin T, Li Y, et al. Long non-coding RNA LEF1-AS1 promotes migration, invasion and metastasis of colon cancer cells through miR-30-5p/SOX9 Axis. Onco Targets Ther. 2020;13:2957-72.

Tam OH, Aravin AA, Stein P, Girard A, Murchison EP, Cheloufi S, et al. Pseudogene-derived small interfering RNAs regulate gene expression in mouse oocytes. Nature. 2008; 453(7194):534-8.

Tang H, Brennan J, Karl J, Hamada Y, Raetzman L, Capel B. Notch signaling maintains Leydig progenitor cells in the mouse testis. Development. 2008; 135:3745-53.

Taylor DH, Chu ET, Spektor R, Soloway PD. Long non-coding RNA regulation of reproduction and development. Mol Reprod Dev. 2015;82: 932-56.

Teranishi M, Shimada Y, Hori T, Nakabayashi O, Kikuchi T, Macleod T, et al. Transcripts of the MHM region on the chicken $\mathrm{Z}$ chromosome accumulate as non-coding RNA in the nucleus of female cells adjacent to the DMRT1 locus. Chromosome Res. 2001;9:147-65.

Torley KJ, da Silveira JC, Smith P, Anthony RV, Veeramachaneni DN, Winger QA, et al. Expression of miRNAs in ovine fetal gonads: potential role in gonadal differentiation. Reprod Biol Endocrinol. 2011;9:2.

Uchida S, Dimmeler S. Long noncoding RNAs in cardiovascular diseases. Circ Res. 2015;116: 737-50.
Wainwright EN, Jorgensen JS, Kim Y, Truong V, Bagheri-Fam S, Davidson T, et al. SOX9 regulates MicroRNA miR-202-5p/3p expression during mouse testis differentiation. Biol Reprod. 2013;89:34.

Wang F, Yang Q. Long Non-Coding RNA LINC01089 enhances the development of gastric cancer by sponging mir- $145-5 p$ to mediate SOX9 expression. Onco Targets Ther. 2020;13:9213-24.

Wang Q, Liu S, Zhao X, Wang Y, Tian D, Jiang W. MiR-372-3p promotes cell growth and metastasis by targeting FGF9 in lung squamous cell carcinoma. Cancer Med. 2017;6:1323-30.

Wang Y, Huang Q, Li F. miR-140-5p targeted FGF9 and inhibited the cell growth of laryngeal squamous cell carcinoma. Biochem Cell Biol. 2019;98:83-9.

Watanabe T, Totoki Y, Toyoda A, Kaneda M, Kuramochi-Miyagawa S, Obata Y, et al. Endogenous siRNAs from naturally formed dsRNAs regulate transcripts in mouse oocytes. Nature. 2008;453(7194):539-43.

Windley SP, Wilhelm D.Signaling Pathways Involved in Mammalian Sex Determination and Gonad Development. Sex Dev. 2015;297-315.

Wu Q, Song R, Ortogero N, Zheng H, Evanoff R, Small CL, et al. The RNase III enzyme DROSHA is essential for microRNA production and spermatogenesis. J Biol Chem. 2012;287: 25173-90.

Wu PH, Fu Y, Cecchini K, Özata DM, Arif A, Yu $\mathrm{T}$, et al. The evolutionarily conserved piRNAproducing locus pi6 is required for male mouse fertility. Nat Genet. 2020a;52:728-39.

Wu S, Xu R, Zhu X, He H, Zhang J, Zeng Q, et al. The long noncoding RNA LINC01140/miR140-5p/FGF9 axis modulates bladder cancer cell aggressiveness and macrophage M2 polarization. Aging (Albany NY). 2020b;12: 25845-64.

Wu Y, Tao L, Liang J, Qiao Y, Liu W, Yu H, et al. miR-187-3p increases gemcitabine sensitivity in breast cancer cells by targeting FGF9 expression. Exp Ther Med. 2020c;20:952-60.

Xu Y, An JJ, Tabys D, Xie YD, Zhao TY, Ren HW, et al. Effect of lactoferrin on the expression profiles of long non-coding RNA during osteogenic differentiation of bone marrow mesenchymal stem cells. Int J Mol Sci. 2019; 20(19):4834.

Xue M, Li G, Sun P, Zhang D, Fang X, Li W. MicroRNA-613 induces the sensitivity of gastric cancer cells to cisplatin through targeting SOX9 expression. Am J Transl Res. 2019;11: 885-94.

Yan N, Lu Y, Sun H, Tao D, Zhang S, Liu W, et al. A microarray for microRNA profiling in mouse testis tissues. Reproduction. 2007;134: 73-9.

Yan H, Liu Q, Jiang J, Shen X, Zhang L, Yuan Z, et al. Identification of sex differentiation-related microRNA and long non-coding RNA in Takifugu rubripes gonads. Sci Rep. 2021; 11(1):7459.
Yang W, Sun P. Downregulation of microRNA129-5p increases the risk of intervertebral disc degeneration by promoting the apoptosis of nucleus pulposus cells via targeting BMP2. J Cell Biochem. 2019;120:19684-90.

Yang X, Zheng J, Xu G, Qu L, Chen S, Li J, et al. Exogenous cMHM regulates the expression of DMRT1 and ER alpha in avian testes. Mol Biol Rep. 2010;37:1841-7.

Yang B, Guo H, Zhang Y, Chen L, Ying D, Dong S. MicroRNA-145 regulates chondrogenic differentiation of mesenchymal stem cells by targeting Sox9. PLoS One. 2011;6:e21679.

Yang Q, Hua J, Wang L, Xu B, Zhang H, Ye N, et al. MicroRNA and piRNA profiles in normal human testis detected by next generation sequencing. PLoS One. 2013;8:e66809.

Yang X, Deng J, Zheng J, Xia L, Yang Z, Qu L, et al. A window of MHM demethylation correlates with key events in gonadal differentiation in the chicken. Sex Dev. 2016;10:152-8.

Yoneda R, Satoh Y, Yoshida I, Kawamura S, Kotani T, Kimura AP. A genomic region transcribed into a long noncoding RNA interacts with the Prss42/Tessp-2 promoter in spermatocytes during mouse spermatogenesis, and its flanking sequences can function as enhancers. Mol Reprod Dev. 2016;83:541-57.

Yoshizawa A, Nakahara Y, Izawa T, Ishitani T, Tsutsumi M, Kuroiwa A, et al. Zebrafish Dmrta2 regulates neurogenesis in the telencephalon. Genes Cells. 2011;16:1097-109.

Yu B, Qian T, Wang Y, Zhou S, Ding G, Ding F, et al. miR-182 inhibits Schwann cell proliferation and migration by targeting FGF9 and NTM, respectively at an early stage following sciatic nerve injury. Nucleic Acids Res. 2012; 40:10356-65.

Yuan S, Ortogero N, Wu Q, Zheng H, Yan W. Murine follicular development requires oocyte DICER, but not DROSHA. Biol Reprod. 2014;91:39.

Zhang L, Lu H, Xin D, Cheng H, Zhou R. A novel ncRNA gene from mouse chromosome 5 trans-splices with Dmrt1 on chromosome 19. Biochem Biophys Res Commun. 2010;400: 696-700.

Zhang P, Kang JY, Gou LT, Wang J, Xue Y, Skogerboe G, et al. MIWI and piRNA-mediated cleavage of messenger RNAs in mouse testes. Cell Res. 2015a;25:193-207.

Zhang YJ, Xu F, Zhang YJ, Li HB, Han JC, Li L. miR-206 inhibits non small cell lung cancer cell proliferation and invasion by targeting SOX9. Int J Clin Exp Med. 2015b;8:910713.

Zhang J, Yu P, Zhou Q, Li X, Ding S, Su S, et al. Screening and characterisation of sex differentiation-related long non-coding RNAs in chinese soft-shell turtle (Pelodiscus sinensis). Sci Rep. 2018;8:8630.

Zhang H, Zhang Z, Gao L, Qiao Z, Yu M, Yu B, et al. miR-1-3p suppresses proliferation of hepatocellular carcinoma through targeting SOX9. Onco Targets Ther. 2019;12:2149-57. 
Zhang WL, Zhao DY, Zhao W, Cui Y, Li Q, Zhang ZY. Effect of lentivirus-mediated miR-182 targeting FGF9 on hallux valgus. Int J Med Sci. 2021;18(4):902-10.

Zhao S, Zhu W, Xue S, Han D. Testicular defense systems: immune privilege and innate immunity. Cell Mol Immunol. 2014;11:428-37.

Zhong J, Tu X, Kong Y, Guo L, Li B, Zhong W, et al. LncRNA H19 promotes odontoblastic dif- ferentiation of human dental pulp stem cells by regulating miR-140-5p and BMP-2/FGF9. Stem Cell Res Ther. 2020;11:202.

Zhou X, Li Q, Lu H, Chen H, Guo Y, Cheng H, et al. Fish specific duplication of Dmrt2: characterization of zebrafish Dmrt2b. Biochimie. 2008;90:878-87.

Zhou Y, Shi H, Du Y, Zhao G, Wang X, Li Q, et al. lncRNA DLEU2 modulates cell proliferation and invasion of non-small cell lung cancer by regulating miR-30c-5p/SOX9 axis. Aging ( $\mathrm{Al}-$ bany NY). 2019;11:7386-401.

Zimmermann C, Romero Y, Warnefors M, Bilican A, Borel C, Smith LB, et al. Germ cellspecific targeting of DICER or DGCR8 reveals a novel role for endo-siRNAs in the progression of mammalian spermatogenesis and male fertility. PLoS One. 2014;9:e107023. 